\title{
TUMBUHAN PAKAN TERNAK LOKAL DI KABUPATEN PANDEGLANG, BANTEN
}

\author{
Bambang R. Prawiradiputra \\ Balai Penelitian Ternak Ciawi \\ PO Box 221 Bogor 16002; Telp 02518240752 \\ bambangrisdiono2@gmail.com
}

\begin{abstract}
ABSTRAK
Pada tahun 2009 Balai Penelitian Ternak bekerjasama dengan Balai Pengkajian Teknologi Pertanian (BPTP) Provinsi Banten dan Dinas Peternakan Kabupaten Pandeglang telah membentuk "Kampoeng Ternak" di Desa Juhut, Kecamatan Karangtanjung, Kabupaten Pandeglang, Provinsi Banten. Kegiatan utamanya adalah membina peternak domba termasuk memperbaiki pakannya. Salah satu kegiatan perbaikan pakan adalah identifikasi jenis-jenis hijauan pakan yang biasa diberikan petani kepada domba yang dipeliharanya. Dari beberapa hijauan pakan yang ditemukan di kandang domba, ada sembilan spesies yang merupakan tumbuhan pakan lokal yang selama ini belum pernah diidentifikasi. Ke sembilan spesies itu (dalam bahasa lokal) adalah kondang (Ficus variegata), beunying (Ficus fustulosa), camun (Pipturus incanus), gedebang (Piper aduncum), hareunga (Gynura aurantica), kareumbi (Homalanthus populnea), ki tongo (Debregeasia longifolia), leles dan nangsi (Villebrunea rubescens). Selain itu ditemukan juga gamal (Gliricidia maculata), kaliandra (Calliandra calothyr sus), jengjen (Falcataria sp.), mani'i (Miopsis sp.), mindi (Melia azedarach), dadap (Erythrina lithosperma) dannangka (Artocarpus integra). Dalam makalah ini dibahas secara ringkas taksonomi, ciri-ciri morfologi dan ekologi dari tumbuhan itu.
\end{abstract}

Kata kunci: tumbuhan pakan lokal, lahan kering, domba.

\begin{abstract}
In 2009 The Indonesian Research Institute for Animal Production in cooperation with The Assessment Institute for Agricultural Technology of Province of Banten and Livestock Service of District of Pandeglang has established the "Kampoeng Ternak" or "Village of Livestock" in the Village of Juhut, Sub-District of Karangtanjung, District of Pandeglang, Province of Banten. Its main activity was to improve sheep breeders including improved its feed. One of the improvements was to identification of the forage commonly given to the sheep. Of some forage found in the sheepfold, there were nine species of plant which was local forage that had never been identified elsewhere before. The nine species were (in local language) kondang (Ficus variegata), beunying (Ficus fustulosa), camun (Pipturus incanus), gedebang (Piper aduncum), hareunga (Gynura aurantica), kareumbi (Homalanthus populnea), ki tongo (Debregeasia longifolia), leles and nangsi (Villebrunea rubescens). In addition it was also found gamal (Gliricidia maculata), kaliandra (Calliandra calothyrsus), jengjen (Falcataria sp.), mani’i (Miopsis sp.), mindi (Melia azedarach), dadap (Erythrina lithosperma) and nangka or jackfruit (Artocarpus integra). In this paper discussed in brief taxonomy, morphological characteristics and ecology of the forage plants.
\end{abstract}

Keywords: local forage, dry land, sheep

\section{PENDAHULUAN}

Indonesia sangat kaya akan ragam tumbuhan, termasuk tumbuhan pakan ternak. Bukan hanya tumbuhan pakan ternak yang sudah biasa diberikan kepada ternak tetapi juga tumbuhan-tumbuhan pakan yang hanya terdapat di wilayah-wilayah tertentu saja. Tumbuhan lokal ini sangat bervariasi tergantung pada ekosistem tempat dimana tumbuhan ini berkembang. Komunitas tumbuhan pakan yang terdapat di dataran rendah berbeda dengan komunitas tumbuhan yang berada di dataran tinggi, demikian juga komunitas tumbuhan yang berkembang di wilayah iklim basah berbeda dengan di wilayah iklim kering. Komunitas tumbuhan yang berkembang di padang rumput berbeda dengan komunitas tumbuhan di ekosistem sawah.

Belum banyak peneliti Indonesia yang mengidentifikasi spesies-spesies tumbuhan pakan yang berkembang di ekosistem tertentu. Dari sedikit peneliti itu antara lain Heyne (1950) dengan bukunya yang fenomenal "De Nuttige Planten van Indonesie", menginventarisasi begitu banyak spesies tumbuhan yang terdapat di Indonesia, termasuk di dalamnya tumbuhan pakan. Nullik dan Bamualim (1998) sudah mengidentifikasi tumbuhan pakan ternak yang berkembang di padang rumput Nusa Tenggara Timur. Prawiradiputra (1986) mengidentifikasi tumbuhan 
pakan lokal yang terdapat di Daerah Aliran Sungai (DAS) Jratunseluna di Jawa Tengah dan DAS Brantas di Jawa Timur. Di Lembang, Hanafiah dan Prawiradiputra (2009) mendapatkan bahwa antara $27 \%$ sampai $57 \%$ hijauan yang ditemukan di kandang sapi perah adalah hijauan pakan lokal, dimana sekitar $13 \%$ di antaranya adalah daun-daunan dari pohon yang hanya diberikan pada musim kemarau saja.

Di luar Indonesia beberapa peneliti juga sudah menginventarisasi tumbuhan pakan di wilayahnya masing-masing seperti Panday di Nepal (1982), Punj (1988) dan Gupta (1988) juga menuliskan daftar tumbuhan pakan yang digunakan peternak di Asia Selatan. Tentu masih ada peneliti lain baik di Indonesia maupun di luar Indonesia yang namanya tidak masuk di dalam makalah ini.

Tumbuhan pakan lokal ini tentu sangat penting untuk diinventarisasi, khususnya tumbuhan-tumbuhan yang memiliki potensi untuk dikembangkan lebih lanjut sebagai tumbuhan pakan unggul. Berdasarkan fakta tersebut perlu dikembangkan lebih lanjut inventarisasi tumbuhan-tumbuhan pakan lokal yang terdapat di berbagai agroekosistem di Indonesia. Makalah ini menampilkan beberapa spesies tumbuhan pakan di agroekosistem lahan kering iklim basah di Banten yang apabila dipelajari lebih lanjut akan sangat bermanfaat bagi perkembangan peternakan di Indonesia.

\section{MATERI DAN METODE}

Pengamatan hijauan pakan dilakukan bersamaan dengan Participatory Rural Appraisal (PRA) untuk menentukan layak tidaknya Desa Juhut dijadikan laboratorium "kampoeng ternak".

Untuk mengetahui potensi hijauan pakan yang ada di Kampung Cinyurup, telah dilakukan survey potensi hijauan selama lima bulan, mulai dari bulan April sampai Agustus 2009. Pengamatan dilakukan terhadap sample peternak yang diawali pada bulan Januari 2009. Dari sejumlah 60 peternak domba di Kampung Cinyurup diambil 23 peternak secara purposif, yaitu mereka yang memenuhi persyaratan untuk dijadikan kooperator di dalam pemeliharaan ternak selanjutnya. Pengamatan penggunaan hijauan dilakukan dengan cara mengambil sampel hijauan di kandang dan dianalisis komposisinya sebagaimana yang pernah dilakukan sebelumnya di beberapa lokasi (Prawiradiputra, 1986).

Data yang diambil meliputi identifikasi spesies yang terdapat di kandang, bobot segar setiap spesies dari setiap kandang dan frekuensi keberadaan. Data ditampilkan dalam Indeks Nilai Penting (INP=important value) dan Sum Dominance Ratio (SDR), meminjam metode yang biasa digunakan oleh peneliti ekologi tumbuhan (Cox, 1972; Dumbois dan Ellenberg, 1974), baik pada musim kemarau maupun pada musim hujan. Berdasarkan INP dan SDR dapat ditentukan spesies-spesies apa saja yang paling banyak dan paling sering diberikan kepada ternak di setiap peternak.

\section{HASIL DAN PEMBAHASAN}

Agroekosistem Kabupaten Pandeglang, Banten

Berdasarkan agroekosistem Indonesia dibagi menjadi enam agroekosistem yaitu agroekosistem lahan kering iklim basah, lahan kering iklim kering, lahan beririgasi, lahan rawa dan pasang surut, lahan kering di daerah aliran sungai dan lahan tadah hujan (Manwan, 1989). Kabupaten Pandeglang termasuk ke dalam agroekosistem lahan kering iklim basah dengan curah hujan antara 2000 sampai $4000 \mathrm{~mm}$ per tahun (Banten Dalam Angka, 2011). Di dalam klasifikasi Oldeman Kabupaten Pandeglang termasuk ke dalam tipe iklim B2 dengan 6-7 bulan basah berturut-turut dan musim kemarau sekitar 4-5 bulan dalam satu tahun.

Berdasarkan tingkat kesuburan lahan, dilaporkan bahwa mayoritas lahan di lokasi termasuk lahan subur, dilaporkan bahwa semakin tinggi lokasi, lahannya semakin subur.

Tabel 1. Jenis hijauan pakan lokal yang biasa diberikan kepada domba di Kampung Juhut Pandeglang

\begin{tabular}{|c|c|c|c|}
\hline No. & Nama lokal & Nama latin & Keterangan \\
\hline 1 & Sauheun & Panicum palmifolium & Rumput lokal \\
\hline 2 & Aawian & Panicum montanum & Rumput lokal \\
\hline 3 & Jampang beureum & Eragrotis japonica & Rumput lokal \\
\hline 4 & Jampang hejo & & Rumput lokal \\
\hline 5 & Jampang munding & Eulesine indica & Rumput lokal \\
\hline 6 & Gigirinting & Cynodon dactylon & Rumput lokal \\
\hline 7 & Rumput pahit & Paspalum conjugatum & Rumput lokal \\
\hline 8 & Kaliandra & Calliandra calothyrsus & Leguminosa perdu \\
\hline 9 & Gamal/cebreng & Gliricidia maculata & Leguminosa perdu \\
\hline 10 & Jengjen/sengon & Albizia falcataria & Leguminosa pohon \\
\hline 11 & Alpuket & Persea americana & Pohon non leguminosa \\
\hline 12 & Camun & Pipturus incanus & Pohon non leguminosa \\
\hline 13 & Mani'i/sobsi & Miopsis sp. & Pohon non leguminosa \\
\hline 14 & Kareumbi/kareumi & Homalanthus populneus & Pohon non leguminosa \\
\hline 15 & Hareunga & Gynura aurantica & Pohon non leguminosa \\
\hline 16 & Beunying & Ficus fustulosa & Pohon non leguminosa \\
\hline 17 & Nangsi & Villebrunea rubescens & Pohon non leguminosa \\
\hline 18 & Mindi & Melia azedarach & Pohon non leguminosa \\
\hline 19 & Mindi gede & Melia dubia & Pohon non leguminosa \\
\hline 20 & Gedebang & Piper aduncum & Perdu non leguminosa \\
\hline 21 & Kacapi tuheur & Elaeocarpus macrophyna & aPerdu non leguminosa \\
\hline 22 & Kacapi monyet & Sandorium kucape & Perdu non leguminosa \\
\hline 23 & Kondang & Ficus variegata & Pohon non leguminosa \\
\hline 24 & Ki Tongo & Debregeasia longifolia & Pohon non leguminosa \\
\hline 25 & Dadap & Erythrina lithosperma & Pohon non leguminosa \\
\hline 26 & Leles & & Pohon non leguminosa \\
\hline
\end{tabular}

\section{Spesies-spesies yang diberikan kepada ternak}

Pada Tabel 1 dirangkum jenis-jenis hijauan yang dapat diinventarisasi dan diidentifikasi. Dapat dilihat bahwa sebagian besar jenis hijauan pakan yang tersedia di lokasi pengamatan adalah jenis-jenis berdaun lebar yang berasal dari pohon. Rumput lokal yang dapat diidentifikasi hanya berjumlah tujuh spesies yaitu sauheun (Panicum palmifolium), a'awian ( $P$. montanum), jampang beureum (Eragrotis japonica), jampang hejo, jampang munding (Eulesine indica), gigirinting (Cynodon dactylon), dan rumput pahit (Paspalum conjugatum). Rumput gajah (Pennisetum 
purpureum) dan setaria (Setaria sphacelata) juga ditemukan di kandang tetapi dua spesies terakhir ini adalah rumput introduksi yang masuk ke lokasi pengamatan karena adanya bantuan ternak domba.

Leguminosa juga sudah ada di lokasi pengamatan namun masih sangat terbatas, yaitu kaliandra (Calliandra calothyrsus), gamal (Gliricidia maculata) dan jengjen (Albizia falcataria). Selain itu leguminosa lain adalah leguminosa tanaman pangan seperti kacang tanah (Arachis hypogea) dan buncis (Phaseolus sp.) yang sudah lama dibudidayakan masyarakat di sana. Tanaman pangan lain yang daunnya diberikan kepada ternak domba adalah ubi jalar, jagung dan ubi kayu namun di Kampung Cinyurup daun ubi jalar, jagung dan ubi kayu masih jarang diberikan karena peternak beranggapan bahwa rumput masih banyak tersedia dan rumput lebih baik daripada daun ubi jalar, jagung dan ubi kayu.

\section{Komposisi hijauan di kandang}

Data pada Tabel 2 menunjukkan bahwa pada musim hujan lebih dari 50\% hijauan yang diberikan adalah rumput lokal, sedangkan rumput introduksi tidak ada. Demikian juga halnya dengan leguminosa. Sisa hasil dan hasil ikutan tanaman pangan yang diberikan kepada ternak sekitar 22\% dan daun-daunan (ramban) memberikan kontribusi sekitar $24 \%$.

Tidak adanya rumput introduksi yang ditemukan di kandang pada musim penghujan karena rumput gajah dan setaria baru diperkenalkan dan baru ditanam di lahan tanaman pangan sebagai tanaman pematang sehingga pada saat pengambilan data belum ada yang dipangkas. Sedangkan persentase rumput lokal sangat tinggi karena pada musim hujan rumput lokal tumbuh subur di lahan-lahan pertanian maupun di pinggirpinggir jalan dan pinggir hutan. Data ini sesuai dengan hasil survei yang dilakukan Prawiradiputra (1986) di Jawa Tengah dan Jawa Timur maupun yang dilakukan Hanafiah dan Prawiradiputra (2009) di Jawa Barat.

Tabel 2. Jumlah Spesies dan Summed Dominance Ratio (SDR) hijauan pakan yang ditemukan di kandang

\begin{tabular}{llrrrr}
\hline \multirow{2}{*}{ No. Jenis hijauan pakan } & \multicolumn{3}{c}{ Musim hujan } & \multicolumn{3}{c}{ Musim kemarau } \\
\cline { 2 - 6 } & $\begin{array}{c}\text { Jumlah } \\
\text { spesies }\end{array}$ & SDR & $\begin{array}{c}\text { Jumlah } \\
\text { spesies }\end{array}$ & SDR \\
\hline 1 & Rumput local & 7 & 53,88 & 7 & 36,76 \\
2 & Rumput introduksi & 0 & 0 & 2 & 7,00 \\
3 & Daun leguminosa & 0 & 0 & 3 & 12,58 \\
4 & Daun non-leguminosa & 11 & 24,45 & 17 & 36,76 \\
5 & Sisa hasil pertanian & 8 & 21,67 & 7 & 7,53 \\
\hline
\end{tabular}

*)Angka SDR diperoleh dari rata-rata frekuensi dan Indeks Nilai Penting

Pada musim kemarau rumput lokal yang diberikan berkurang, yaitu hanya $36 \%$, tetapi ada rumput introduksi sekitar $7 \%$. Sementara rambanan meningkat menjadi $36 \%$ dari $24 \%$. Sisa hasil pertanian juga menurun menjadi $7 \%$, tetapi daun leguminosa cukup banyak diberikan yaitu $12 \%$. Pada bulan Agustus (musim kemarau) rumput gajah dan setaria sudah dipangkas dan diberikan kepada ternak. Pada musim ini rumput lokal di lapangan tidak sebanyak pada musim hujan sehingga yang diarit petani juga berkurang, sebagai gantinya petani mengambil hijauan yang berupa daun-daun pohon yang terdapat di pinggir-pinggir hutan sehingga komposisi daun pohon non-leguminosa meningkat.

Beberapa spesies pohon lokal di Desa Juhut, Banten

\section{Beunying}

Nama lain : ara, kara, ki ara, kayu ara, buruniburuni

Famili : Moraceae (suku nangka-nangkaan)

Genus : Ficus

Spesies : Ficus fistulosa Reinw. ex Blume

Deskripsi : Pohon hingga $20 \mathrm{~m}$ dengan diameter bisa mencapai $25 \mathrm{~cm}$. Batang dengan getah putih. Stipula sekitar $10 \mathrm{~mm}$, Daun sederhana, Diameter buah berukuran $10 \mathrm{~mm}$, kuning-coklat, bulat, berdaging. Buah ara dalam bundel bersama ranting dan batang.

Habitat : Tumbuh baik di hutan-hutan pegunungan sampai ketinggian $1700 \mathrm{~m}$. Di lereng-lereng bukit dengan tanah liat berpasir. Di hutan sekunder biasanya ditemukan sebagai sisa setelah pembabadan hutan.

Penyebaran : Mulai dari India timur laut dan Cina selatan sampai ke Papua Nugini. Di Borneo terkonsentrasi di Sarawak, Sabah dan Kalimantan Timur.

Pemanfaatan selain sebagai pakan : Pucuk daun dimakan mentah (obat mencret) Buahnya dapat dimakan.

\section{Ki Camun}

Nama lain : Senu, Lilit kutu (Melayu), Games (Lampung), Ki Camun (Sunda), Senu, Trebesi (Jawa), Baylabayan, (Madura), Kosir (Ambon), Lobiri (Halmahera,Ternate)

Famili : Urticaceae

Genus : Pipturus

Spesies : Pipturus incanus (Bl.) Wedd Kerabat dekat : Waru putih

Deskripsi : Pohon, tinggi5-20 m.Tegak, bulat, percabangan simpodial, permukaan kasar, bergetah, coklat. Daun tunggal, tersusun spiral, bentuk jantung, ujung runcing, pangkal bertoreh, tepi bergerigi, panjang 10-27 cm, lebar 10$17 \mathrm{~cm}$, pertulangan menyirip, kasar, hijau. Bunga majemuk, bentuk bulir atau malai, berumah satu, panjang bulir 5-10 cm, bertonjolan, hijau. Buah buni, bulat panjang, hijau. Bulat telur, kecil, putih. Akar tunggang, coklat.

Habitat : Biji yang sudah lama terkubur masih bisa tumbuh walaupun di bawah tegakan hutan yang lebat. Perkecambahannya cukup cepat. 
Asal dan penyebaran : Di sekitar Lautan Hindia, Malesia, Australia bagian utara, sampai ke pulau-pulau di Pasifik.

Kandungan kimia : Daun dan kulit batang ki camun mengandung saponin, di samping itu kulit batangnya juga mengandung flavonoida dan tanin.

Manfaat lain : Sebagai obat luka bakar, bisul dan memar digunakan kulit batang dan daun ki camun yang dicuci dan ditumbuk halus lalu ditempelkan pada bagian yang luka kemudian dibalut dengan kain bersih. Selain itu daunnya juga digunakan untuk pencuci rambut (pembasmi kutu). Serat dari batang bisa digunakan sebagai pembuat tali.

\section{Seuseureuhan}

Nama lain : Seuseureuhan (Sunda), sirihan

Famili : Piperaceae

Genus : Piper

Spesies : Piper aduncum L.

Deskripsi : Batang berkayu, ujung runcing, pangkal membulat, tepi rata pada setiap buku, tangkai berbulu halus, silindris 5-10 $\mathrm{mm}$, panjang daun 10-14 $\mathrm{cm}$, lebar 5-6 $\mathrm{cm}$, pertulangan menjari, hijau muda. Bunga majemuk, bentuk buli, berkelamin satu atau dua, daun pelindung bertangkai $0,5-1,25 \mathrm{~mm}$, melengkung, tangkai benang sari pendek, kepala sari kecil, bakal buah duduk, kepala putik dua sampai tiga, pendek, putih, putih kekuningan. Buah: buni, bertangkai pendek, panjang bulir 12-14 cm, masih muda kuning kehijauan, setelah tua hijau. Biji: kecil, coklat. Akar: tunggang, putih kecoklatan (Syamsuhidayat dan Hutapea, 1991).

Habitat : Areal perkebunan, hutan alami; liana Penyebaran : Data sementara menunjukkan hanya terdapat di Pulau Jawa

Kandungan kimia : Daun seuseureuhan mengandung saponin, flavonoida, polifenol, minyak atsiri, dihydrochalcone, piperaduncin A, B, C, dan asebogenin (Orjala et al., 2004).

Manfaat lain :Getah batangnya berkhasiat sebagai obat bisul dan obat luka baru. Untuk obat bisul, dipakai getah batang \pm 2 ml, kemudian dioleskan pada bisul.

\section{Hareunga}

$\begin{array}{ll}\text { Nama lain } & : \text { Hareunga } \\ \text { Famili } & : \text { Asteraceae } \\ \text { Genus } & : \text { Gynura } \\ \text { Spesies } & : \text { Gynura aurantica } \\ \text { Deskripsi } & : \text { perdu berkayu, tahunan. Daunnya } \\ & \text { selalu hijau dengan rambut-rambut } \\ & \text { halus merah muda, tingginya 1-2 }\end{array}$

meter dengan lebar tajuk 1,5 m. Batangnya yang tegak, lunak dan lemah. Bunganya berwarna kuningoranye, biasanya tidak keluar apabila kurang cahaya matahari.

Penyebaran : Tumbuhan asli Pulau Jawa, sekarang sudah menyebar sampai ke benua Amerika sebagai tanaman hias.

Manfaat lain : Tanaman hias

\section{Kareumbi}

Nama lain : Kareumbi

Famili : Euphorbiaceae

Genus : Homalanthus

Spesies : Homalanthus populneus (Giesel)Pax.

Deskripsi : Pohon tinggi, bisa sampai $10 \mathrm{~m}$, bergetah putih. Daunnya panjang, sampai $15 \mathrm{~cm}$ Bunganya aksilaris, tidak bercabang, biseksual. Bentuk seludang bunganya satu untuk beberapa pasang kelenjar. kelopak berbentuk ginjal; benang sari 4-30. Buah berbentuk kapsul berkayu, bijinya tebal.

Habitat : Biasanya tumbuh didalam hutan sekunder dengan ketinggian sampai $3000 \mathrm{~m}$ dpl., tetapi sering juga dijumpai di tempat-tempat yang dibersihkan, di perkebunan, sisi jalan, lereng curam; Tumbuh baik di berbagai jenis tanah, dari dangkal sampai dalam, tanah miskin hara maupun subur.

Penyebaran : Tumbuhan asli Malesia, Mulai dari semenanjung Malaysia, Thailand Selatan, Sumatera, Jawa, Kalimantan, Sulawesi, Nusa Tenggara Barat, Maluku, Filipina kemudian menyebar ke Taiwan sampai ke Australia, Selandia Baru dan Pasifik Barat.

Kandungan kimia : Belum diketahui

Manfaat lain : Buah digunakan untuk mengobati luka. Daunnya sering digunakan oleh ibu-ibu setelah melahirkan dengan meletakkannya di perut, atau untuk obat demam. Kulit dan daun digunakan untuk pencelupan kain agar berwarna kehitaman. Daun kering yang dibubukkan dan dicampur dengan pakan digunakan sebagai vermifuge pada ternak; Sedangkan daun yang ditumbuk dicampur dengan abu dan merica bertindak sebagai racun ikan. Kayunya bernilai rendah tetapi merupakan kayu bakar yang baik. Kareumbi cocok untuk reboisasi di tanah yang baik.

\section{Ki Tongo}

Nama lain : Totongoan

Famili : Urticaceae

Genus : Debregeasia 

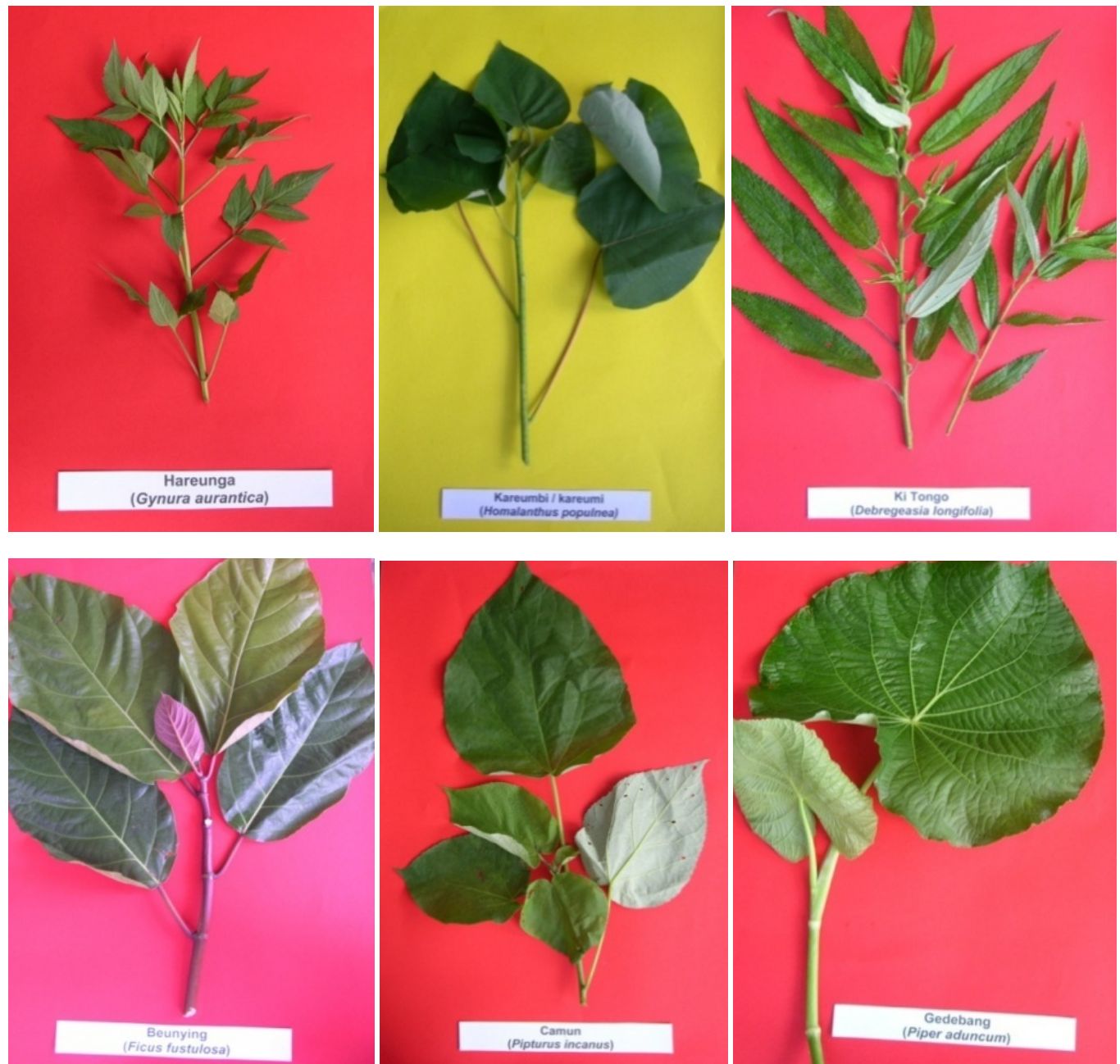

Spesies

Deskripsi

Habitat

: Debregeasia longifolia (N. L. Burman) (Burm.f.) Wedd.

Perdu atau pohon kecil tingginya 3-6 m, Anak cabang samping yang ramping, kemerahan, atau coklat keunguan. Permukaan daun bagian atas kasar dan berwarna hijau, sedangkan permukaan bagian bawah berwarna putih-kelabu. Daun hijau gelap berbentuk-ellips, kadang-kadang nyaris bulat telur, Karangan bunga tumbuh dari bagian ketiak daun. Buah yang sudah masak berwarna merah, dan dapat dimakan, rasanya asam.

Spesies ini merupakan tumbuhan khas di lahan-lahan suksesi, atau lahan yang sedang mengalami pemulihan dari kerusakan. lembab, di lembah-lembah dengan ketinggian 500-3200 $\mathrm{m} \mathrm{dpl}$.

Penyebaran : Cina selatan, Bangladesh, Bhutan, Kamboja, India, Indonesia, Laos, Malaysia, Myanmar, Nepal, Filipina, Sikkim, Sri Lanka, Thailand, Vietnam
Kandungan kimia : Tidak ada data

Manfaat lain :Seratnya berkualitas tinggi

\section{SIMPULAN}

Hasil pengamatan di Desa Juhut, Kabupaten Pandeglang, Provinsi Banten menunjukkan bahwa banyak potensi tumbuhan pakan lokal yang belum dimanfaatkan dengan maksimal. Eksplorasi jenis-jenis tumbuhan pakan, tidak hanya di Banten tetapi juga di seluruh Indonesia perlu dilakukan agar potensi yang ada dapat dimanfaatkan.

Inventarisasi jenis-jenis tumbuhan pakan lokal juga perlu segera dilakukan antara lain dengan membuat buku. Peranan HITPI dalam hal ini sangat strategis karena HITPI tidak mengenal pembatasan wilayah atau lokasi kegiatan.

\section{DAFTAR PUSTAKA}

Anon., 2008. Data Monografi Kelurahan Juhut. Pemkab Pandeglang.

Bamualim, A., 2009. The Dynamics of Native Grass Resources in Dry Area of Indonesia to Support Beef Cattle Production: The Case Study of Nusa Tenggara. In Lee and Bejosano (eds). Sustainable Management and Utilization of Forage- 
based Resources for Small-scale Livestock Farmers in Asia. Proceeding of the international Seminar on Sustainable Management and Utilization of Forage-based Resources for Small-scale Livestock Farmers in Asia. Lembang Indonesia. Food and Fertilizer Technology Center for the Asian and Pacific Region, Indonesian Research Institute for Animal Production.

Chew, W.-L., 1989. Urticaceae. In: George, A.S. (Editor): Flora of Australia. Vol. 3. Hamamelidales to Casuarinales. Australian Government Publishing Service, Canberra, Australia. pp. 68-93.

Cox, G.W., 1972. Laboratory Manual of General Ecology. W.M. Brown Co. Publisher, Iowa.

Devendra, C., 1988. Strategies for the Intensive Utilization of the Feed Resources in the Asian Region. In Devendra (ed). Non-conventional Feed Resources and Fibrous Agricultural Residues. Proc. A Consultation held in India. International Development Resarch Center and Indian Council of Agricultural Resarch.

Dumbois, D. M. and H. Ellenberg, 1974. Aims and Methods of Vegetation Ecology. John Willey \& Sons. New York.

Enright, N., 1985. Existence of a soil seed bank under rainforest in New Guinea. Australian Journal of Ecology 10(1): 67-71.

Gupta, B.S., 1988. Availability and utilization of non-conventional feed resources and their utilization by non-ruminants in South Asia. In Devendra (ed). Non-conventional Feed Resources and Fibrous Agricultural Residues. Proc. A Consultation held in India. International Development Resarch Center and Indian Council of Agricultural Resarch.

Hanafiah, A. dan B. R. Prawiradiputra' 2009. Forage Composition at Small-Scale Dairy Farm In Lembang, Indonesia. In Lee and Bejosano (eds). Sustainable Management and Utilization of Forage-based Resources for Small-scale Livestock Farmers in Asia. Proceeding of the international Seminar on Sustainable Management and Utilization of Forage-based Resources for Small-scale Livestock Farmers in Asia. Lembang Indonesia. Food and Fertilizer Technology Center for the Asian and Pacific Region, Indonesian Research Institute for Animal Production.
Heyne, K ., 1950. De Nuttige Planten van Indonesie. W. van Hoeve. Bandung.

Locher, C.P., Burch, M.T., Mower, H.F., Berestecky, J., Davis, H., Van Poel, B., Lasure, A., Van den Berghe, D.A. \& Vlietinck, A.J., 1995. Anti-microbial activity and anti-complement activity of extracts obtained from selected Hawaiian medicinal plants. Journal of Ethnopharmacology 49(1): 23-32.

Manwan, I., 1989. Farming Systems Research in Indonesia: Its evolution and Future Outlook. In Sukmana et al. (eds). Developments in Procedures for Farming Systems Research. Proc. International Workshop. Bogor, Indonesia.

Nullik, J, dan A. Bamualim, 1998. Pakan Ruminansia Besar di Nusa Tenggara. BPTP, Naibonat dan EIVSP AusAID.

Orjala, J., Wright A.D., Behreds, H., Folkers, G., Sticher, O., Ruegger, H., Rail, T.(1994).'Cytotoxic and Antibacterial Dyhidrohalcones from Piper aduncum', J. Nat. Prod., Jan; 57(1):18-26

Panday, K., 1982. Fodder Trees and Tree Fodder in Nepal. Swiss Development Cooperation, Berne, Switzerland. Swiss Federal Institute of Forestry Research. Switzerland.

Prawiradiputra, B. R., 1986. Pola Penggunaan Hijauan Makanan Ternak di DAS Jratunseluna dan DAS Brantas. Badan Litbang Pertanian. 26 hal.

Punj, M.L., 1988. Availability and utilization of non-conventional feed resources and their utilization by ruminants in South Asia. In Devendra (ed). Non-conventional Feed Resources and Fibrous Agricultural Residues. Proc. A Consultation held in India. International Development Resarch Center and Indian Council of Agricultural Resarch.

Syamsuhidayat, S. S., dan Hutapea, J. R., 1991, Inventaris Tanaman Obat Indonesia (I), Departemen Kesehatan RI, Jakarta, page 452-453

van Valkenburg, J.L.C.H., 2001. Pipturus Wedd. In: van Valkenburg, J.L.C.H. and Bunyapraphatsara, N. (Editors). Plant Resources of South-East Asia No. 12(2): Medicinal and poisonous plants 2. Backhuys Publisher, Leiden, The Netherlands, pp. 430-432. 